\title{
Protección de los derechos de los ciberconsumidores en la Comunidad Andina de Naciones
}

\author{
Protection of the rights of cyberconsumers in the Andean Community of Nations
}

\section{Proteger os direitos dos ciberconsumidores na Comunidade Andina das Nações}

Artículo recibido en enero 2021

Arbitraje en febrero 2021

Aceptación en marzo 2021

Publicación en abril 2021
Diego Fernando Pino Cuellar

pinocuellardiego@gmail.com

https://orcid.org/0000-0001-9887-0116

Universidad Andina Simón Bolívar, Quito-Ecuador
RESUMEN

ABSTRACT

$$
\text { us }
$$

In recent years, electronic commerce of goods and services has grown exponentially, thanks to the development of the mo that consumers can access more products and suppliers can increase their sales. Likewise, the objective of the study was to analyze the characteristics of the cybertrade laws of the countries of the Andean Community of Nations in order to generate a regulation that allows the protection of the rights of cyberconsumers in Bolivia, Colombia, Ecuador and Peru. It is an analytical research since it considers the weaknesses and strengths of different legislations in order to recompose criteria in a new and future regulation. The design is a documentary design of comparative legal analysis and the population is constituted by the legal sources that refer to cybertrade in the CAN countries and at international level. As a result, the possibility and options of using the method of adopting a community norm that approximates the legislations of the CAN countries for the protection of cyberconsumers in the regulation of electronic commerce operations is proposed.

Key words: Cyberconsumers; cybercommerce; electronic commerce; consumer protection; Andean Community of Nations

En los últimos años ha crecido exponencialmente el comercio electrónico de bienes servicios, gracias al desarrollo del uso de las tecnologías de la información y la comunicación (TIC), eliminado fronteras entre los países y borrando las limitaciones fisicas para que los consumidores puedan acceder a más productos y para que los proveedores puedan aumentar sus países de la Comunidad Andina de Naciones para generar una normativa que permita la protección de los derecio de los de los ciberconsumidores en Bolivia, Colombia Ecuador y Perú. Es una investigación analítica ya que se consideran las debilidades y fortalezas de diferentes legislaciones para recomponer criterios en una nueva y futura normativa. El diseño es documental de análisis jurídico comparado y la población está constituida por las fuentes legales que hacen referencia al cibercomercio en los países de la CAN y a nivel internacional. Como resultado se plantea la posibilidad y las opciones de usar el método de la adopción de una norma comunitaria que aproxime las legislaciones de los países de la CAN para la protección de los ciberconsumidores en la regulación de las operaciones de comercio electrónico.

Palabras clave: Ciberconsumidores; cibercomercio; comercio electrónico; protección al consumidor; Comunidad Andina de Naciones de tecnologias de informação e comunicação (TICS), eliminando fronteiras entre países e apagando limitações físicas para que os consumidores possam ter acesso a mais produtos e os fornecedores possam aumentar suas vendas. Da mesma forma, o objetivo do estudo foi analisar as características das leis de cibercomércio dos países da Comunidade Andina de Nações, a fim de gerar uma regulamentação que permita a proteção dos direitos dos ciberconsumidores na Bolívia, Colômbia, Equador e Peru. É uma pesquisa analítica, pois considera os pontos fracos e fortes de diferentes legislações a fim de recompor critérios em uma nova e futura regulamentação. O projeto é uma análise jurídica comparativa documental e a população é composta por fontes legais que se referem ao comércio eletrônico nos países da CAN e em nível internacional. Como resultado, são consideradas a possibilidade e as opções de usar o método de adotar uma norma comunitária que se aproxime da legislação dos países da CAN para a proteção dos ciberconsumidores na regulamentação das operações de comércio eletrônico.

Palavras-chave: Cyber-consumidores; cyber-comércio; comércio eletrônico; proteção ao consumidor; Comunidade Andina de Nações 
La pandemia del COVID-19 potenció todas las actividades basadas en las redes de Tecnología de la Información y la Comunicación (TIC), una de las áreas de mayor crecimiento es la del comercio a través de plataformas en línea, la cual recibe distintas denominaciones como cibercomercio, comercio virtual o comercio electrónico.

Este tipo de comercio trae un cambio en la forma de hacer negocio a nivel internacional, aparecen nuevos términos como el ciberconsumidor que es el usuario que compra o contrata un producto o un servicio valiéndose de una plataforma virtual. El cibercomercio o comercio electrónico es un fenómeno jurídico, económico y social en el que se produce una contratación de productos o servicios a través de medios informáticos.

A nivel internacional existe una tendencia para la estimulación del comercio electrónico, lo que se evidencia por las acciones de diferentes instituciones y organizaciones, así la Organización para la Cooperación y el Desarrollo Económico (OCDE) emitió entre otras la Recomendación sobre lineamientos para la protección al consumidor en el contexto del comercio electrónico del 9 de diciembre de 1999, asimismo, la Comisión de las Naciones Unidas para el Derecho Mercantil Internacional (CNUDMI) desarrolló una Ley Modelo sobre Comercio Electrónico y una Ley Modelo sobre Firmas Electrónicas.

La Ley Modelo sobreComercio Electrónico desarrolla nociones de no discriminacióny neutralidad respecto de los medios técnicos y equivalencia funcional, asimismo, establece normas para la formación y la validez de los contratos concertados por medios electrónicos, para la atribución de los mensajes de datos, para el acuse de recibo y para la determinación del lugar y hora en que se envíen y reciban los mensajes de datos, lo que permite comprender que una de las principales tareas de los ordenamientos jurídicos en cuanto al comercio electrónico, es determinar cómo se le puede dar validez legal y probatoria a toda la actividad que se produce en el seno de intercambios comerciales realizados a través de mecanismos electrónicos. Los documentos electrónicos, concebidos por la doctrina jurídica se entienden como "cualquier representación en forma electrónica de hechos jurídicamente relevantes, susceptibles de ser asimilados en forma humanamente comprensible" (Sala de Casación de la República de Colombia, 2010). El principio de equivalencia funcional es clave en la consideración de relaciones comerciales a través de medios tecnológicos, pues permite entenderlos a través de conocimientos tradicionales "ius privatistas", sin tener que asumir que se trata de categorías jurídicas totalmente diferentes, lo que sin duda simplifica la reflexión jurídica, no significando ello en lo absoluto que por esta situación se deben obviar los retos de regulación que igualmente se encuentran presentes al considerar el uso de la tecnología en las relaciones humanas.

La más reciente encuesta de Harvey Nash, con más de 30 años de experiencia en el sector tecnológico, y la firma KPMG, especializada en auditoría y asesoramiento con presencia en 147 países, reveló que la pandemia del coronavirus generó una de las mayores inversiones en tecnología de la historia. Los resultados de la encuesta, durante la primera ola de la pandemia 
las compañías gastaron cerca de US\$15.000 millones adicionales a la semana en tecnología. Además del gasto en inversión se han dado cambios organizacionales en la forma como se desarrolla el trabajo, la relación con los clientes y proveedores todo de forma remota (Harvey Nash, 2020).

Asimismo, el cibercomercio ha traído graves problemas de seguridad, en Suramérica, el $46 \%$ de los líderes en tecnología aseguró haber experimentado un incremento en la cantidad de ciberataques durante la covid-19. Los más frecuentes fueron por 'phishing', 'malware' y 'denial of service attack'; esto trae como consecuencia problemas entre el proveedor y el cliente en el cibercomercio.

Las situaciones de conflicto crecen de manera importante en relación al comercio electrónico, las quejas de los ciberconsumidores se producen por diferentes causas entre ellas: (a) productos o servicios no recibidos; (b) Incumplimiento de las políticas de devolución; (c) Imposibilidad de contactar con el proveedor; (d) Calidad baja o deficiente de los productos suministrados; (e) Uso no autorizado de identidad, (f) facturación de productos no solicitados; (g) Equivocación de productos o servicios no conforme con la orden de compra; (h) Incumplimiento de la garantía, y; (i) Cobros ocultos, (j) problemas de seguridad de la plataforma, entre otras (Econsumer, 2011).

El cibercomercio o comercio electrónico abarca una amplia gama de actividades posibles como intercambios de información, publicidad, marketing online, reserva de productos, contratación de servicios, compra y pago de bienes, no se limita a la compra y venta de bienes y servicios, pues tiene un ámbito amplísimo de acción y por tanto de regulación. Todo negocio jurídico verificado telemáticamente en el que exista una contraprestación económica por el servicio ofrecido al usuario, también tiene implícito el uso de la red para actividades anteriores y posteriores a ese negocio jurídico o completamente ajenas a un negocio patrimonial tal como la búsqueda de información, la participación en foros o "chats", las comunicaciones comerciales, manejo de información de los usuarios.

Los ciberconsumidores del comercio electrónico, no tienen plena confianza al utilizar este medio, y muchas veces lo hacen asumiendo riesgos por ser atraídos con ofertas que pueden parecer sumamente atractivas; sin embargo muchas veces, a causa de la falta de regulación en la materia este ciberconsumidor puede tener problemas como la violación de su privacidad, la utilización indebida de sus datos personales y/o la insatisfacción en la compra o servicio contratado. (Cendoya, 2001).

Uno de los problemas que surge en el comercio electrónico es el desconocimiento de cuáles son las leyes o normas nacionales o internacionales que puedan ser útiles para la protección al ciberconsumidor, generalmente éste se ve obligado a aceptar los contratos de adhesión predefinidos por quien es proveedor o vendedor. La existencia de un vacío acerca de la regulación a la cual se somete una operación de comercio electrónico; nacional, internacional, comunitaria, jurisdicciones especiales, a la libre voluntad de las partes trae como consecuencia la falta de una verdadera política de protección del consumidor, lo cual puede generar 
conflictos legales. Actualmente no existe un instrumento propio en la Comunidad Andina de Naciones (CAN) que regule el derecho aplicable a los contratos internacionales que incluya los celebrados por vía electrónica en todas sus variantes y específicamente aquellas transacciones en las que participan los usuarios o ciberconsumidores.

Este artículo ofrece un análisis de las diferentes leyes, de los países de la CAN y algunos referentes internacionales, que regulan los derechos de los ciberconsumidores y establece las razones para la existencia de una normativa comunitaria que regule los derechos de los consumidores del comercio electrónico; las cuales se convertirán en un antecedente sólido para que se pueda concretar su realización por parte de la Comunidad Andina.

Se realiza el análisis de las legislaciones de los cuatros países miembros de la CAN: Bolivia, Colombia, Ecuador y Perú, respecto a este tema; así como también se revisan otros cuerpos normativos complementarios los cuales son considerados como información útil para generar la fundamentación.

El aporte central del presente trabajo, es en primer lugar, diagnosticar la vulnerabilidad de los derechos de los consumidores en el comercio electrónico y en segundo lugar, plantear líneas de reflexión en torno a buscar la posibilidad de que pueden existir mecanismos subregionales que permitan una mejor y mayor protección de estos derechos.

La interrogante que plantea la investigación es ¿Cuáles son las características de una normativa de cibercomercio entre los países de la CAN, para garantizar la protección de los derechos de los ciberconsumidores?

Asimismo se declara como objetivo del estudio analizar las características de las leyes de cibercomercio de los países de la Comunidad Andina de Naciones para generar una normativa que permita la protección de los derechos de los ciberconsumidores en Bolivia, Colombia Ecuador y Perú.

MÉTODO

Es una investigación analítica ya que se consideran las debilidades y fortalezas de diferentes legislaciones para recomponer criterios en una nueva y futura normativa. El diseño es documental de análisis jurídico comparado y la población está constituida por las fuentes legales que hacen referencia al cibercomercio en los países de la CAN y a nivel internacional.

RESULTADOS

Para el análisis de las legislaciones se consideran la existencia de los siguientes elementos: (a) Presencia en la Constitución de la base legal para normar el cibercomercio, (b) Ley específica y estructura organizativa que se encarga de la regulación y cumplimiento de los derechos del consumidor, (c) Definición de términos relacionados con el cibercomercio, (d) Derechos del consumidor contemplados en la normativa legal. 


\section{Legislación de Bolivia}

Los derechos de usuarios y consumidores, tiene reconocimiento constitucional, el Art. 75 de la Constitución Política del Estado de Bolivia (CPE Bolivia, 2009), el cual establece que los consumidores gozan de los derechos al suministro de alimentos, fármacos y productos en general, en condiciones de inocuidad, calidad, y cantidad disponible adecuada y suficiente, con prestación eficiente y oportuna del suministro y a la información fidedigna sobre las características y contenidos de los productos que consuman y servicios que utilicen. Estos derechos de la protección del consumidor, poseen un status de derechos fundamentales, y tienen como sustento los principios constitucionales de vivir bien, justicia social, protección, integralidad, integridad y favorabilidad.

Con base en estos derechos se dicta la Ley 453 (2013, Diciembre 6) o Ley General de los Derechos de las Usuarias y los Usuarios y de las Consumidoras y Consumidores la cual es una ley específica que rige las relaciones de consumo y en particular los derechos de los consumidores.

La estructura organizativa del Poder Ejecutivo del estado Plurinacional de Bolivia cuenta con el Viceministerio de Defensa de los Derechos del Usuario y Consumidor, bajo tuición del Ministerio de Justicia, que tiene como función establecer los procedimientos para la admisión, gestión y seguimiento de las denuncias por incumplimiento de normas y regulaciones en la prestación de servicios y suministro de productos, asimismo se crean las autoridades de control y fiscalización en varios sectores de actividades económicas a efectos de que puedan entre otras actividades velar por la protección del consumidor.

La Ley 453 en su Art. 5 define los términos de consumidor, proveedor, producto, servicio y relación de consumo. El consumidor es la persona natural o jurídica que adquiere, utiliza o disfruta productos o servicios, como destinatario final, es decir, descarta totalmente la posibilidad de que ingrese en la definición la noción genérica de cliente como consumidor y se limita a que éste debe ser el destinatario final del producto, sin hacer ninguna distinción entre consumidor jurídico y material.

El proveedor. Lo define de una forma amplia, señalando que es la persona natural o jurídica, pública o privada, que desarrollan actividades de producción, fabricación, importación, suministro, distribución, comercialización y otras, de productos o de prestación de servicios en general destinados directamente a los consumidores finales, excluyendo expresamente de su definición a quienes ejercen profesiones libres, acá de la definición que se otorga al proveedor debemos rescatar en primer término que la legislación boliviana determina el alcance de relaciones de consumo también a escenarios en los que el Estado aparece como proveedor de bienes y servicios. Es de hacer notar que se excluyen a las profesiones liberales aparentemente para que los casos de negligencia o atención deficitaria sean analizados desde otra perspectiva distinta a la de las relaciones entre consumidores y proveedores. 
El producto. Es todo bien que se ofrece en el mercado para satisfacer necesidades de uso y consumo final. El servicio son las actividades suministradas o provistas al mercado, destinadas a satisfacer necesidades o requerimientos incluidos los servicios básicos. En este sentido la relación de consumo se define como el vínculo que se establece entre el proveedor, que provee un producto o presta un servicio, y quien lo adquiere, utiliza o consume como destinatario final.

\section{Derechos del consumidor previstos en la legislación boliviana}

1. Derecho a la salud y a la integridad física. Los artículos de la CPE que están relacionados con el derecho de todos los habitantes de una comunidad a pedir y recibir por parte del Estado prestaciones básicas y necesarias mínimas, que conlleven una vida saludable, son: 7, 13। 16, 18 $, 19,20,46,75,76,88,89,104,135$.

En este mismo orden de ideas los artículos 8 y 9 de la Ley 453, estipulan que los productos que se reciban deben estar en condiciones de inocuidad (OMS. 2007). El art. 9 determina que los proveedores están obligados a suministrar productos o servicios en condiciones de inocuidad, calidad y seguridad, siendo responsables penal, civil y administrativamente del riesgo o daño causados a la salud e integridad física de los consumidores, así mismo se hace corresponsables a las autoridades competentes que no hubieran asumido las medidas de seguridad necesarias.

La Constitución del estado Plurinacional de Bolivia (CPE) y la Ley General de los Derechos de las Usuarias y los Usuarios y de las Consumidoras y los Consumidores, establecen el contenido mínimo de los derechos de los usuarios y consumidores, señalando las condiciones del suministro de productos y la información sobre las características de los productos (arts. art. 75.1 y 75.2 de la CPE respectivamente, que en términos de la Ley específica citada involucran derechos de consumidores y deberes de proveedores, así como responsabilidades de los órganos públicos competentes. De ahí que, la protección de los derechos de los consumidores y usuarios también trasciende una rama concreta del derecho, nutriéndose de diferentes ramas jurídicas que prevén distintos mecanismos de protección tanto en la vía administrativa como en la judicial, con un sistema complejo de normas, principios, instituciones y medios instrumentales consagrados por el ordenamiento jurídico, para procurar al consumidor y usuario una posición de equilibrio dentro del mercado en sus relaciones de consumo y uso. Son estas las razones que subyacen para concluir que un consumidor o usuario tiene varias opciones para la tutela de sus derechos, que, dependiendo del grado de su afectación pueden ser: vía acción popular o vía acción de amparo constitucional, esta última, una vez agotados los recursos administrativos o judiciales previstos en la Ley General de los Derechos de las usuarias y los usuarios y de las consumidoras y los consumidores. 
2. Derecho a la alimentación. Este derecho es reconocido por el art 16 de la CPE Bolivia, asimismo, la Sección II de la Ley 453 denominado derecho y condiciones para la alimentación, se estipula que los consumidores tienen derecho al acceso a alimentos autorizados, de manera regular, permanente, continua y libre, cuantitativa y cualitativamente adecuados y suficientes, estableciéndose que las condiciones en las que se elabora, manipulan y conservan serán reglamentados por la autoridad competente, y que el proveedor que suministra alimentos de primera necesidad tiene la obligación de suministrarlos de manera adecuada, oportuna, continua y a precio justo.

3. Derecho a la información. La Ley 453, determina que los consumidores tienen derecho a recibir información fidedigna, veraz, completa, adecuada, gratuita y oportuna sobre las características y contenidos de los productos que consuman y servicios que utilicen, es decir, existe un mandato imperativo para los proveedores de buscar los mecanismos de información suficientes para que en todo momento el consumidor tenga información suficiente sobre las características y contenidos del producto evitando brindar información que no sea veraz, por ejemplo a través de publicidad engañosa o abusiva esto lo tipifica en el artículo 5.

Los artículos 14 y 15 han precisado los deberes del proveedor de productos o servicios en relación a la información que deben brindar a los consumidores, estableciendo entre otros que estos tienen los deberes siguientes:

- Proporcionar información sobre: (a) las características del producto: su composición nutricional, forma de uso o conservación, posibles riesgos que puedan afectar la salud e integridad física, que provengan del consumo o uso del producto o servicio. (b) la calidad del producto o del servicio y con las especificaciones de sus características principales. (c) el precio total en moneda nacional que incluya los tributos, comisiones y cargas que correspondan, ello incluye informar sobre ajustes de tarifas en los servicios, así como el rango de precios que estén disponibles para un mismo producto o servicio. (d) la información debe estar en idioma castellano, de ser necesario a través de etiquetas complementarias y, en lo posible, en otro idioma oficial del Estado. (e) la variedad de productos o servicios de similares características, para que los consumidores puedan asumir una decisión favorable a sus intereses.

Toda información proporcionada por el proveedor, ya sea de manera impresa, adherida al envase o en otro soporte o digital, adquiere calidad de documento público a partir de la autorización de importación, distribución o comercialización otorgada por la autoridad competente, en consecuencia estos documentos dan plena fe, respecto a la oferta o las condiciones de la misma, por ello la normativa (art. 16.II de la Ley 453), estipula que puede existir responsabilidad penal por alteración posterior de dicha información. 
4. Derecho al trato equitativo. Los artículos 5,17 y 18 de la Ley 453 , establecen que los consumidores tienen derecho a un trato equitativo por parte de los proveedores en la oferta de sus productos o servicios sin discriminación para una persona o un grupo de personas.

5. Derecho a la libre elección de productos y servicios. El artículo 24 de la Ley 453, determina que consumidores tienen derecho a elegir los productos y servicios que requieran, al igual que seleccionar o cambiar de proveedor. En ese sentido se estipula que los proveedores no pueden ordenar o inducir a contratar con determinados proveedores o quienes proporcionen servicios auxiliares.

6. Derecho a la reclamación. Los consumidores tienen derecho a la reclamación, esta figura es el mecanismo procesal directo creado por el Legislador boliviano a efectos de que éstos reclamen la transgresión de los derechos antes mencionados; este derecho se puede ejercer en primera instancia ante el proveedor, el cual tiene la obligación de responder el mismo positiva o negativamente, en caso de que la respuesta sea negativa o ésta no exista se abre para el consumidor la vía administrativa denominada también como reclamación, su procedimiento está establecido en la propia Ley 453 (arts. 51 y siguientes).

La figura de la reclamación tiene por finalidad la inmediata restitución del derecho vulnerado al consumidor, se rige por los principios que rigen el Derecho Administrativo, en Bolivia se tiene la Ley de Procedimiento Administrativo (LPA), que en su artículo 4 establece algunos de los principios que inspiran a la actividad administrativa, y son aplicable a los procedimientos administrativos por la previsión expresa del art. 46 de la LPA.

La Ley 453, regula algunos rubros específicos de consumo, como los servicios básicos, médicos y bancarios o financieros, estableciendo disposiciones específicas para cada una de ello sin olvidar que siempre se aplican los derechos y principios anteriormente expuestos de manera transversal a todos estos ámbitos en general.

Ley 164 o Ley general de Telecomunicaciones, Tecnologías de Información y Comunicación

Esta Ley regulan los aspectos de cibercomercio estipula algunas nociones en materia de comercio electrónico, de documentos y firmas digitales.

En su artículo 1, contempla la garantía de la distribución equitativa y el uso eficiente del recurso natural y limitado del espectro radioeléctrico; asegurar el ejercicio del derecho al acceso universal y equitativo a los servicios de telecomunicaciones, tecnologías de información y comunicación, así como del servicio postal; garantiza el desarrollo y la convergencia de redes de telecomunicaciones y tecnologías de información y comunicación.

El Estado es responsable, en todos sus niveles de gobierno, de la provisión de los servicios de telecomunicaciones y tecnologías de información y comunicación, así como del servicio postal, a través de entidades públicas, mixtas, cooperativas, comunitarias y en el caso de 
telecomunicaciones también a través de empresas privadas, mediante autorizaciones o contratos.

El artículo 78 de la Ley 164, señala que tiene validez jurídica el acto o negocio jurídico realizado por persona natural o jurídica en documento digital y aprobado por las partes a través de firma digital, celebrado por medio electrónico u otro de mayor avance tecnológico, también reconoce la validez del mensaje electrónico de datos y la firma digital.

El artículo 6 hace referencia a la firma digital o electrónica la cual identifica únicamente a su titular, creada por métodos que se encuentren bajo el absoluto y exclusivo control de su titular, susceptible de verificación y está vinculada a los datos del documento digital de modo tal que cualquier modificación de los mismos ponga en evidencia su alteración.

Sin embargo de dichas precisiones no todos los actos jurídicos realizados a través de documentos digitales tienen validez legal en el Estado Plurinacional de Bolivia, pues la Ley 164, expresamente excluye la validez de documentos relativos al derecho de familia, aquellos en los que la Ley requiera la concurrencia personal o física de alguna de las partes, o aquellos que requieran un documento físico.

La ley 164, se constituye en un primer paso hacia la regulación del comercio electrónico en Bolivia, sin embargo la propia Ley advierte la necesidad de una ley específica para el comercio electrónico.

En el artículo 85 de esta Ley se establece que la oferta de bienes y servicios por medios digitales, que cumplan con las condiciones generales y específicas que la Ley impone, debe ser realizada en un ambiente técnicamente confiable y en las condiciones que establece el Código de Comercio, al respecto, de dicha disposición es difícil comprender qué pretende establecer con la definición de técnicamente confiable, y a qué condiciones del Código de Comercio se refiere, seguramente eso será clarificado en la legislación específica que surja en la materia.

Asimismo en el art. 86 de la Ley 164 se valida y posiciona la existencia de los contratos electrónicos en el derecho interno boliviano, estipulando que las partes podrán realizar transacciones comerciales mediante documento digital en las condiciones señaladas en la Ley, salvo en los contratos en los cuales la Ley o el mismo contrato excluyan expresamente la validez de los documentos digitales, sin embargo, también reconoce el valor probatorio de documentos digitales, así estos carezcan de firma digital. Finalmente se previene que en caso de controversias las partes se someterán a la jurisdicción estipulada en el contrato, a falta de ésta, se sujetarán a la autoridad administrativa boliviana si corresponde y en su caso a la jurisdicción ordinaria.

En síntesis podemos afirmar que existe legislación específica y especial nueva en materia de derecho de la defensa de los consumidores, reconociéndose hoy varios derechos emergentes 
de la relaciones de consumo para estos, independientemente de que éstas se desarrollen por medios físicos o electromagnéticos, ello sumado al reconocimiento legislativo de los documentos digitales y el comercio electrónico generan un camino marcado para que en Bolivia existen disposiciones especiales tendientes a la protección de los derechos de los ciberconsumidores.

Sin embargo no cabe duda alguna que existe un vacío acerca de la protección de los consumidores frente al comercio electrónico internacional, esta vulnerabilidad es tema de este artículo.

A continuación se analizan las legislaciones de los países miembros de la CAN.

\section{Legislación de Colombia}

La Legislación colombiana tiene un origen constitucional y tiene la finalidad de establecer parámetros de orden público a efectos de erradicar las asimetrías propias de las relaciones de consumo entre los consumidores y los proveedores. El organismo que se encarga de los asuntos referentes al consumidor es el Ministerio de Comercio, Industria y Turismo y la Superintendencia de Protección al Consumidor.

En Colombia la protección de los consumidores se rige por la Ley 1480 de 12 de octubre de 2011, la cual ha instituido el Estatuto del Consumidor, el mismo que contiene una amplia gama de regulación en materia de protección del consumidor, en principio esta norma estipula que tiene como objetivos proteger, promover y garantizar la efectividad y el libre ejercicio de los derechos de los consumidores, así como amparar el respeto a su dignidad y a sus intereses económicos, de ahí que al igual que la Ley boliviana vemos que es una norma cuya finalidad más que dar regulación a las relaciones de consumo es establecer prerrogativas en favor de los consumidores frente a los proveedores de bienes o servicios.

El artículo 1 de la Ley 1480 tiene como objetivos proteger a los consumidores frente a riesgos para su salud y seguridad, garantizar el acceso la información, brindar educación al consumidor, garantizar la libertad de constituir organizaciones de consumidores, brindar protección especial a los niños y adolescentes consumidores.

El artículo 5 define al consumidor como la persona natural como destinatario final que adquiere, disfrute o utilice un determinado producto para satisfacer una necesidad propia no vinculada a su actividad económica.

La Ley 1480, enumera y describe brevemente el alcance del contenido de los derechos del consumidor son los mismos que se reconocen en la legislación boliviana. Entre los derechos citados en el texto legal, están los derecho a recibir productos de calidad, a la seguridad e indemnidad, a recibir información, a recibir protección contra la publicidad engañosa, a 
la reclamación, a la protección contractual, a la libre elección de productos o servicios, a la participación, de representación, a informar, a la educación y a la igualdad, entro otros ampliamente desarrollados en el transcurso del Estatuto del Consumidor.

Esta legislación tiene disposiciones específicas en materia de garantías, destinadas a garantizar el buen funcionamiento del producto o servicio y están ligadas con el derecho a recibir productos de calidad, estas garantías se definen en términos generales como las obligaciones a cargo de todo productor y/o proveedor de responder por la calidad, idoneidad, seguridad y el buen estado y funcionamiento de los productos, regulándose al respecto los términos y condiciones para su ejecución, disposiciones ampliamente desarrolladas a diferencia de la ya estudiada legislación boliviana que no prevé una legislación semejante.

Lo relativo al cibercomercio la legislación colombiana contempla en el artículo 46 de la Ley 1480 lo relativo a las ventas a distancia, determina las obligaciones del productor o proveedor que las realiza, estipulando que éste deberá cerciorarse la entrega del bien o servicio en la dirección indicada por el consumidor que ha sido debidamente identificado, asimismo, deberá permitir que el consumidor haga reclamaciones y devoluciones, también se estipula que el proveedor mantenga los registros necesarios e informe sobre la disponibilidad del producto, el derecho de retracto, el término de duración de las condiciones comerciales y el tiempo de entrega. El mencionado derecho al retracto se contempla en el artículo 47 de la Ley 1480 por el cual puede pedir un reembolso dentro de los 5 días de recibido el bien de consumo.

En cuanto a los ciberconsumidores la Ley 1480, determina un régimen específico, independientemente que exista una norma específica para el comercio electrónico, que es la Ley 527, la que justamente estipula en su art. 46 una suerte de prevalencia de las leyes de protección al consumidor señalando que la norma se aplicará sin perjuicio de las normas vigentes en materia de protección al consumidor.

El art. 49 de la Ley 1480 define el comercio electrónico en las relaciones de consumo, señalando que se trata de "...la realización de actos, negocios u operaciones mercantiles concertados a través del intercambio de mensajes de datos telemáticamente cursados entre proveedores y los consumidores para la comercialización de productos y servicios"; no existe nada que diferencie sustancialmente al comercio electrónico del tradicional (civil - comercial), en relaciones de consumo, desde la perspectiva del uso y regulación de la tecnología, que será exactamente la misma.

También el artículo 50 de la Ley 1480 estipula las obligaciones de los proveedores en cuanto al comercio electrónico de consumo, y a partir de esas obligaciones se pueden identificar algunos derechos específicos y propios de estas relaciones. Los derechos que contempla son a la (a) identificación comercial del proveedor o productor; (b) información digital del 
producto ofertado; (c) información sobre los medios de pago, entrega del producto, derecho al retracto y condiciones del contrato; (d) constancia de la transacción; (e) protección de datos del ciberconsumidor; (f) obtención de un soporte digital brindado por el proveedor; (g) reversión del pago.

\section{Legislación de Ecuador}

La Constitución Política de Ecuador incorpora en el 2008 los derechos de los consumidores, en los artículos 53 y 55 contemplan los derechos a disponer de bienes y servicios de buena calidad, elegirlos libremente, a la información precisa y no engañosa sobre contenido y características, a constituir asociaciones de protección del consumidor entre otros, así también se incorpora una interesante y novedosa obligación para empresas, instituciones y organismos que presten servicios públicos de incorporar sistemas de medición de satisfacción de los consumidores.

En Ecuador existe desde el año 2000 la Ley de Defensa del Consumidor (LDC) de y su Reglamento (Decreto Ejecutivo 1314), que se constituyen en normas de protección al consumidor.

El art. 4 de la LDC, estipula los derechos del consumidor ecuatoriano, lo cual obviamente no implica limitar los antes señalados derechos reconocidos por la Constitución de Ecuador, y señala los siguientes: (a) Derecho a la protección de la vida, salud y seguridad en el consumo de bienes y servicios, así como a la satisfacción de las necesidades fundamentales y el acceso a los servicios básicos; (b) Derecho a que proveedores públicos y privados oferten bienes y servicios competitivos, de óptima calidad, y a elegirlos con libertad; (c) Derecho a recibir servicios básicos de óptima calidad; (d) Derecho a la información adecuada, veraz, clara, oportuna y completa sobre los bienes y servicios ofrecidos en el mercado, así como sus precios, características, calidad, condiciones de contratación y demás aspectos relevantes de los mismos, incluyendo los riesgos que pudieren prestar; (e) Derecho a un trato transparente, equitativo y no discriminatorio o abusivo por parte de los proveedores de bienes o servicios, especialmente en lo referido a las condiciones óptimas de calidad, cantidad, precio, peso y medida; ( $f$ ) Derecho a la protección contra la publicidad engañosa o abusiva, los métodos comerciales coercitivos o desleales; (g) Derecho a la educación del consumidor; (h) Derecho a la reparación e indemnización por daños y perjuicios, por deficiencias y mala calidad de bienes y servicios; (i) Derecho a recibir el auspicio del Estado para la constitución de asociaciones de consumidores y usuarios, cuyo criterio será consultado al momento de elaborar o reformar una norma jurídica o disposición que afecte al consumidor; (j) Derecho a acceder a mecanismos efectivos para la tutela administrativa y judicial de sus derechos e intereses legítimos, que conduzcan a la adecuada prevención, sanción y oportuna reparación de los mismos; (k) Derecho a seguir las acciones administrativas y /o judiciales que correspondan; $y(l)$ Derecho a que en las empresas o establecimientos se mantenga un libro de reclamos que estará a disposición del consumidor, en el que se podrá anotar el reclamo correspondiente, lo cual será debidamente reglamentado. 
Adicional a la LPC el Ecuador cuenta con una ley específica la Ley de Comercio Electrónico, Firmas Electrónicas y Mensajes de Datos (LCEFEMD) (Ley No. 2002-67), en la cual se atiende lo relativo al comercio electrónico y los derechos de los ciberconsumidores.

El artículo 49 de la LCEFEMD, establece que el uso de medios electrónicos será válido únicamente si (a) El consumidor ha consentido expresamente en tal uso y no ha objetado tal consentimiento; y (b) El consumidor en forma previa a su consentimiento ha sido informado, a satisfacción, de forma clara y precisa, sobre: 1 . Su derecho u opción de recibir la información en papel o por medios no electrónicos; 2 . Su derecho a objetar su consentimiento en lo posterior y las consecuencias de cualquier tipo al hacerlo, incluidas la terminación contractual o el pago de cualquier tarifa por dicha acción; 3. Los procedimientos a seguir por parte del consumidor para retirar su consentimiento y para actualizar la información proporcionada 4. Los procedimientos para que, posteriormente al consentimiento, el consumidor pueda obtener una copia impresa en papel de los registros electrónicos y el costo de esta copia, en caso de existir.

El artículo 50 de la LCEFEMD, es genérico en sentido que señala que en la prestación de servicios electrónicos en el Ecuador, el consumidor deberá estar suficientemente informado de sus derechos y obligaciones, se puede interpretar que el alcance de dicha norma es expansivo no sólo a la situación de que el proveedor se encuentre en territorio ecuatoriano, sino a que pueda ser únicamente el consumidor que se encuentra en dicho territorio, independientemente de que el proveedor opere desde otro país.

En materia de publicidad y promoción la Ley garantiza que el consumidor pueda acceder a toda la información disponible sobre un bien o servicio sin restricciones, en las mismas condiciones y con las facilidades disponibles para la promoción del bien o servicio de que se trate. El usuario de redes electrónicas, podrá optar o no por la recepción de mensajes de datos que, en forma periódica, sean enviados con la finalidad de informar sobre productos o servicios de cualquier tipo.

\section{Legislación de Perú}

En Perú la base de legislación en materia de protección al ciberconsumidor se encuentra en la Ley 29571, que es el Código de Protección y Defensa del Consumidor (CPDC), establece su finalidad en el artículo II, consiste que los consumidores accedan a productos y servicios idóneos y que gocen de los derechos y los mecanismos efectivos para su protección, reduciendo la asimetría informativa, corrigiendo, previniendo o eliminando las conductas y prácticas que afecten sus legítimos intereses.

Sobre el ámbito de aplicación de la norma, determina que la norma se aplicará para proteger al consumidor que se encuentre directa o indirectamente comprometido con una relación de consumo, y que se aplicará la norma cuando las relaciones de consumo se produzcan el territorio peruano o cuando produzcan sus efectos en este. 
En cuanto a las definiciones de los términos de consumidores y proveedor la norma peruana es ilustrativa en la medida en que no es limitativa, así el artículo 4 del CPDC, señala que se entenderá por usuarios o consumidores a: (a) Las personas naturales o jurídicas que adquieren, utilizan o disfrutan como destinatarios finales productos o servicios materiales e inmateriales, en beneficio propio o de su grupo familiar o social, actuando así en un ámbito ajeno a una actividad empresarial o profesional; (b) Los microempresarios que evidencien una situación de asimetría informativa con el proveedor respecto de aquellos productos o servicios que no formen parte del giro propio del negocio; (c) En caso de duda sobre el destino final de determinado producto o servicio, se califica como consumidor a quien lo adquiere, usa o disfruta.

También se define a los proveedores como las personas naturales o jurídicas, de derecho público o privado, que de manera habitual fabrican, elaboran, manipulan, acondicionan, mezclan, envasan, almacenan, preparan, expenden, suministran productos o prestan servicios de cualquier naturaleza a los consumidores. Determinando que es posible considerar como proveedores a: (a) Distribuidores o comerciantes; (b) Productores o fabricantes; (c) Importadores; (d) Prestadores. Los principios de la norma peruana de protección al consumidor se encuentran en el art. 5 del CPDC, reconociéndose entre otros, los de soberanía del consumidor, pro consumidor, transparencia, corrección de la asimetría, buena fe, pro asociativo, primacía de la realidad.

Los derechos se contemplan en el artículo 6 del CDPC), los cuales son: (a) Derecho a una protección eficaz respecto de los productos y servicios dañinos, que puedan significar un riesgo o peligro para la vida, salud e integridad física. (b) Derecho a acceder a información oportuna, suficiente, veraz y fácilmente accesible, relevante para tomar una decisión o realizar una elección de consumo que se ajuste a sus intereses, así como para efectuar un uso o consumo adecuado de los productos o servicios. (c) Derecho a la protección de sus intereses económicos y en particular contra las cláusulas abusivas, métodos comerciales coercitivos, cualquier otra práctica análoga e información interesadamente equívoca sobre los productos o servicios. (d) Derecho a un trato justo y equitativo en toda transacción comercial y a no ser discriminados por ningún motivo. (e) Derecho a la reparación o reposición del producto, a una nueva ejecución del servicio, o en los casos previstos en el presente Código, a la devolución de la cantidad pagada, según las circunstancias. (f) Derecho a elegir libremente entre productos y servicios idóneos y de calidad, conforme a la normativa pertinente, que se ofrezcan en el mercado y a ser informados por el proveedor sobre los que cuenta. (g) A la protección de sus derechos mediante procedimientos eficaces, céleres o ágiles, con formalidades mínimas, gratuitos o no costosos, según sea el caso, para la atención de sus reclamos o denuncias ante las autoridades competentes. (h) Derecho a ser escuchados de manera individual o colectiva a fin de defender sus intereses por intermedio de entidades públicas o privadas de defensa del consumidor, empleando los medios que el ordenamiento jurídico permita. (i) Derecho a la reparación y a la indemnización por daños y perjuicios conforme a las disposiciones del presente Código y a la normativa civil sobre la materia. (j) Derecho a asociarse con el fin de proteger sus derechos e 
intereses de manera colectiva en el marco de las relaciones de consumo. (k) Derecho al pago anticipado o prepago de los saldos en toda operación de crédito, en forma total o parcial, con la consiguiente reducción de los intereses compensatorios generados al día de pago y liquidación de comisiones y gastos derivados de las cláusulas contractuales pactadas entre las partes, sin que les sean aplicables penalidades de algún tipo o cobros de naturaleza o efecto similar.

Además de lo señalado la norma profundiza aspectos relativos a la información, publicidad, idoneidad de productos (garantías), salud y seguridad, protección de intereses sociales y económicos, contratos, métodos comerciales abusivos, protección del consumidor en servicios específicos (servicios públicos, servicios de salud, servicios educativos, servicios inmobiliarios, servicios de crédito), responsabilidades y sanciones, defensa colectiva de los consumidores, justicia de consumo, entre otros preciados en dicha norma, todos ellos aplicables a operaciones realizadas por métodos de comercio electrónico, cabe acotar que en Perú se encuentra vigente la Ley de Firmas y Certificados Digitales (LFCD), por lo que existe un marco regulatorio en materia de validez y seguridad del comercio electrónico.

La Ley de Firmas y Certificados Digitales (LFCD) tiene por objeto regular la utilización de la firma electrónica otorgándole la misma validez y eficacia jurídica que el uso de una firma manuscrita u otra análoga que conlleve manifestación de voluntad. El artículol de esta norma define la firma electrónica como cualquier símbolo basado en medios electrónicos utilizado o adoptado por una parte con la intención precisa de vincularse o autenticar un documento cumpliendo todas o algunas de las funciones características de una firma manuscrita (Davara, de Marcos, 2008).

Asimismo el artículo 3 de la LFCD señala que la firma digital es aquella que utiliza una técnica de criptografía asimétrica, basada en el uso de un par de claves; una privada y una pública las que se encuentran matemáticamente relacionadas entre sí, de tal forma que las personas que conocen la clave pública no puedan derivar de ella la clave privada. Es decir es un método informático que garantiza la autenticidad y seguridad de que una persona brinda su consentimiento generando un mensaje de aceptación que se halla contrastado con información de seguridad a efectos de evitar suplantaciones de identidad $u$ otros usos nocivos que se le pueda dar a la firma digital.

El titular de la firma digital es la persona a la que se le atribuye de manera exclusiva un certificado digital que contiene una firma digital, identificándolo objetivamente en relación con el mensaje de datos, a su vez, el certificado digital es el documento electrónico generado y firmado digitalmente por una entidad de certificación, la cual vincula un par de claves con una persona determinada confirmando su identidad, el mencionado certificado digital contiene los siguientes componente, según el artículo 7 de la LFCD: (a) Datos que identifiquen indubitablemente al suscriptor. (b) Datos que identifiquen a la Entidad de Certificación. (c) La clave pública. (d) La metodología para verificar la firma digital del suscriptor impuesta a un 
mensaje de datos. (e) Número de serie del certificado. (f) Vigencia del certificado. (g) Firma digital de la Entidad de Certificación.

Una ley que reconozca la firma digital de manera específica es de suma importancia pues permite como lo señala la norma peruana que una firma por medios electrónicos tenga la misma validez y credibilidad comercial que una firma manuscrita, lo que sin duda coadyuva en la seguridad del ejercicio del comercio electrónico.

En el Cuadro 1 se resume comparativo jurídico producto del análisis de las normativas de los países de la CAN.

Cuadro 1. Comparación de la normativa de protección al ciberconsumidor.

\begin{tabular}{|c|c|c|c|c|}
\hline Criterio/País & Bolivia & Colombia & Ecuador & Perú \\
\hline $\begin{array}{l}\text { Fundamento } \\
\text { Constitucional }\end{array}$ & $\begin{array}{l}\text { Artículo } 75 \text { de la } \\
\text { Constitución Política del } \\
\text { Estado de Bolivia (CPE } \\
\text { Bolivia, } 2009\end{array}$ & $\begin{array}{l}\text { Artículo } 369 \text { de la } \\
\text { Constitución Política } \\
\text { de Colombia (2011) }\end{array}$ & $\begin{array}{l}\text { Constitución Política } \\
\text { de Ecuador (2008) } \\
\text { Derechos de los } \\
\text { consumidores, } \\
\text { artículos } 53 \text { y } 55\end{array}$ & \\
\hline
\end{tabular}

\begin{tabular}{|c|c|c|c|c|}
\hline $\begin{array}{l}\text { Norma específica } \\
\text { de protección del } \\
\text { consumidor }\end{array}$ & $\begin{array}{l}\text { Ley } 453 \\
\text { (2013, Diciembre 6) o Ley } \\
\text { General de los Derechos } \\
\text { de las Usuarias y los } \\
\text { Usuarios y de las } \\
\text { Consumidoras y } \\
\text { Consumidores } \\
\text { Ley } 164 \text { o Ley General } \\
\text { de Telecomunicaciones, } \\
\text { Tecnologías de } \\
\text { Información y } \\
\text { Comunicación }\end{array}$ & $\begin{array}{l}\text { Ley } 1480 \text { de } 12 \text { de } \\
\text { octubre de } 2011 \\
\text { Ley } 527 \text { específica } \\
\text { para el comercio } \\
\text { electrónico }\end{array}$ & $\begin{array}{l}\text { Ley de Defensa del } \\
\text { Consumidor (2000) } \\
\text { y su Reglamento } \\
\text { (Decreto Ejecutivo } \\
\text { 1314) Ley de Comercio } \\
\text { Electrónico, Firmas } \\
\text { Electrónicas y } \\
\text { Mensajes de Datos } \\
\text { (LCEFEMD) (Ley No. } \\
\text { 2002-67) }\end{array}$ & $\begin{array}{l}\text { Ley } 29571 \text { Código de } \\
\text { Protección y Defensa } \\
\text { del Consumidor } \\
\text { (CPDC) } \\
\text { Ley de Firmas y } \\
\text { Certificados Digitales } \\
\text { (LFCD) }\end{array}$ \\
\hline $\begin{array}{l}\text { Estructura } \\
\text { Organizativa }\end{array}$ & $\begin{array}{l}\text { Viceministerio de } \\
\text { Defensa de los } \\
\text { Derechos del Usuario y } \\
\text { Consumidor, bajo tuición } \\
\text { del Ministerio de Justicia }\end{array}$ & $\begin{array}{l}\text { Ministerio de } \\
\text { Comercio, Industria y } \\
\text { Turismo. } \\
\text { Superintendencia } \\
\text { de Protección al } \\
\text { Consumidor }\end{array}$ & Defensoría del Pueblo & $\begin{array}{l}\text { Instituto Nacional } \\
\text { de Defensa al } \\
\text { Consumidor (Indecopi) }\end{array}$ \\
\hline $\begin{array}{l}\text { Definición de } \\
\text { términos }\end{array}$ & $\begin{array}{l}\text { Artículo } 5 \text { de la Ley } 453 \\
\text { Consumidor, proveedor, } \\
\text { producto, servicio, } \\
\text { relación de consumo } \\
\text { Artículos } 6,78,85 \\
\text { de la Ley } 164 \text { firma } \\
\text { electrónica, contrato }\end{array}$ & $\begin{array}{l}\text { Comercio electrónico, } \\
\text { consumidor, ventas a } \\
\text { distancia } \\
\text { Firma electrónica } \\
\text { contrato }\end{array}$ & $\begin{array}{l}\text { Condiciones de uso, } \\
\text { consentimiento, } \\
\text { comercio electrónico }\end{array}$ & $\begin{array}{l}\text { Usuarios, } \\
\text { consumidores } \\
\text { Proveedores } \\
\text { Artículo } 4 \text { y } 5 \text { del CPDC } \\
\text { Firma electrónica }\end{array}$ \\
\hline
\end{tabular}




\begin{tabular}{lll}
\hline \multicolumn{1}{c}{ Criterio/País } & \multicolumn{1}{c}{ Bolivia } & \multicolumn{1}{c}{ Colombia } \\
\hline Fundamento & - Derecho a la Salud & - Derecho a la Salud \\
Constitucional & y a la integridad & y a la integridad \\
física; & física; \\
& - Derecho a la & - Derecho a la \\
& alimentación; & alimentación; \\
& - Derecho a la & - Derecho a la \\
& información; & información; \\
& - Derecho al trato & - Derecho al trato \\
& equitativo; & equitativo; \\
- Derecho a la & - Derecho a la \\
& libre elección & libre elección \\
de productos y & de productos y \\
& servicios; & servicios; \\
- Derecho a la & - Derecho a la \\
reclamación. & reclamación.
\end{tabular}

- Derecho a la protección de la vida, salud y seguridad en el consumo de bienes y servicios;

- Derecho a que proveedores públicos y privados oferten bienes y servicios competitivos, de óptima calidad, y a elegirlos con libertad;

- Derecho a recibir servicios básicos de óptima calidad;

- Derecho a la información adecuada, veraz, clara, oportuna y completa sobre los bienes y servicios ofrecidos en el mercado

- Derecho a un trato transparente, equitativo y no discriminatorio o abusivo por parte de los proveedores de bienes o servicios;

- Derecho a la protección contra la publicidad engañosa o abusiva

- Derecho a la educación del consumidor

- Derecho a la reparación e indemnización por daños y perjuicios

- Derecho a recibir el auspicio del Estado para la constitución de asociaciones de consumidores y usuarios

- Derecho a acceder a mecanismos efectivos para la tutela administrativa y judicial de sus derechos e intereses legítimos

- Derecho a seguir las acciones administrativas y /o judiciales

- Derecho a que en las empresas o establecimientos se mantenga un libro de reclamos

\section{Perú}

- Derecho a una protección eficaz respecto de los productos y servicios dañinos;

- Derecho a acceder a información oportuna, suficiente, veraz y fácilmente accesible, relevante;

- Derecho a la protección de sus intereses económicos y en particular contra las cláusulas abusivas;

- Derecho a un trato justo y equitativo en toda transacción comercial y a no ser discriminados por motivo de origen, raza, sexo, idioma, religión, opinión, condición económica o de cualquier otra índole;

- Derecho a la reparación o reposición del producto, a una nueva ejecución del servicio, o en los casos previstos en el presente Código, a la devolución de la cantidad pagada, según las circunstancias;

- Derecho a elegir libremente entre productos y servicios idóneos y de calidad, conforme a la normativa pertinente, que se ofrezcan en el mercado y a ser informados por el proveedor sobre los que cuenta.

- A la protección de sus derechos mediante procedimientos eficaces;

- Derecho a ser escuchados de manera individual o colectiva;

- Derecho a la reparación y a la indemnización por daños y perjuicios;

- Derecho al pago anticipado o prepago de los saldos en toda operación de crédito, en forma total o parcial 


\section{La Unión Europea}

El Tratado de Maastricht de 1992, constitutivo de la Unión Europea, contiene en sus disposiciones el artículo 129 A, que señala: "La Comunidad contribuirá a que se alcance un alto nivel de protección de los consumidores mediante: (a) medidas que adopte en virtud del artículo 100 A en el marco de la realización del mercado interior; (b) acciones concretas que apoyen y complementen la política llevada a cabo por los Estados miembros a fin de proteger la salud, la seguridad y los intereses económicos de los consumidores, y de garantizarles una información adecuada"; con lo cual el Tratado reconoce los derechos de los consumidores a la salud, seguridad, información y protección jurídica, posteriormente con la modificación por medio del Tratado de Ámsterdam se agregaron los derechos a la educación y a la organización para la salvaguarda de sus intereses.

En este mismo orden de ideas la Directiva $97 / 7$ tiene por objeto aproximar las disposiciones legales, reglamentarias y administrativas de los Estados miembros de la Unión europea relativas a los contratos a distancia entre consumidores y proveedores.

El artículo 4 de la Directiva 97/7 establece que el consumidor tiene derecho previamente a celebrar un contrato a distancia a recibir información inequívoca y comprensible, mediante cualquier medio adecuado a la técnica de comunicación a distancia utilizada, respetando los principios de buena fe en materia de transacciones comerciales, la información deberá contener entre otros elementos la identidad del proveedor, su dirección, características esenciales del bien o servicio, precio total, gastos de entrega, modalidades de pago, entrega o ejecución, existencia de un derecho de resolución, plazo de validez de la oferta, duración mínima del contrato. Como complemento el artículo 5 de la Directiva 97/7 dispone que el consumidor tenga el derecho a recibir la confirmación escrita de su solicitud o mediante cualquier otro soporte duradero a su disposición.

El artículo 8 determina que el consumidor puede solicitar la anulación de un pago en caso de utilización fraudulenta de su tarjeta de pago en el marco de contratos a distancia cubiertos por la presente Directiva; un régimen de interdicción de suministros no solicitados, restricciones en la utilización de técnicas de comunicación a distancia para evitar llamadas automáticas y fax.

Todas estas normas tienen un carácter imperativo como lo estipula el artículo 12 de la Directiva, los artículos 13 y 14 determinan las reglas para su aplicación.

\section{El Mercosur}

El Mercosur, es un tratado de libre comercio entre sus países miembros, Argentina, Brasil, Paraguay y Uruguay, su carta constitutiva data del 26 de marzo de 1991 en el Tratado de Asunción, el artículo 1, establece que este Mercado Común implica: (a) La libre circulación de bienes, servicios y factores productivos entre los países, a través, entre otros, de la eliminación 
de los derechos aduaneros y restricciones no arancelarias a la circulación de mercaderías y de cualquier otra medida equivalente. (b) El establecimiento de un arancel externo común y la adopción de una política comercial común con relación a terceros Estados. (c) La coordinación de políticas macroeconómicas y sectoriales. (d) El compromiso de armonizar las legislaciones en las áreas pertinentes, para lograr el fortalecimiento del proceso de integración.

En ese contexto claramente aparece la normativa del consumidor como un factor que hace a la integración del Mercosur, sin embargo hasta ahora lo único que existen son propuestas, como el Proyecto de Protocolo de Defensa del Consumidor del Mercosur o el Protocolo de Santa María sobre Jurisdicción Internacional en Materia de Relaciones de Consumo o la Resolución del Grupo Mercado Común sobre Derecho Aplicable a los Contratos Internacionales de Consumo, pero nada de Legislación vigente, sin embargo como muy bien sostiene Feldstein de Cárdenas y Klein (2011).

Al legislador del MERCOSUR, conforme el compromiso asumido en el artículo $1^{\circ}$ del Tratado de Asunción, le compete instar la armonización legislativa en las áreas pertinentes, de modo tal de evitar distorsiones entre los Estados miembros, y que la ignorancia de las reglas aplicables en países distintos al suyo lleve a los consumidores-usuarios a no realizar transacciones fuera de sus países. En el caso MERCOSUR, la situación dada parecería indicar la conveniencia de un acercamiento a la legislación brasileña, ya que es la que tiende a la mayor protección del consumidor.

\section{CONCLUSIONES}

Existe un vacío jurídico en la regulación del comercio electrónico en Bolivia, por lo cual surge la necesidad de una Ley específica que atienda el cibercomercio y las relaciones entre el ciberconsumidor y el proveedor, con una definición de toda la terminología y alcances del comercio electrónico. De esta forma el ciberconsumidor estará protegido y el proveedor se beneficiará de la seguridad de las transacciones electrónicas.

La nueva normativa debe contemplar el principio de equivalencia funcional en la consideración de relaciones comerciales a través de medios tecnológicos, pues permite enmarcarlos en los conocimientos tradicionales "ius privatistas", sin tener que asumir que se trata de categorías jurídicas totalmente diferentes, lo que sin duda simplifica la reflexión jurídica. Por supuesto que se deben atender las nuevas situaciones y retos de regulación que igualmente se encuentran presentes al considerar el uso de la tecnología en las relaciones humanas.

El comercio electrónico es un fenómeno jurídico, económico y social en el que se produce una contratación de productos o servicios a través de medios informáticos, con lo que se establece que es una modalidad en que la tecnología se pone al servicio del comercio, lo que sucede de manera idéntica con el consumo, puesto que las relaciones de consumo que se realizan en utilización de las tecnologías de la comunicación igualmente no pierden su esencia, por tanto 
se deben separar las relaciones de comercio y las de consumo así sea que ambas se realizan a través de tecnología como internet; puesto que ambas tienen una esencia y finalidades distintas.

El artículo 1 de la Ley Modelo de Comercio Electrónico CNUDMI, que hace referencia a todo tipo de información en forma de mensaje de datos utilizada en el contexto de actividades comerciales, puede remplazarse por actividades de consumo, es decir es una Ley Modelo que va más a regular el medio (la actividad tecnológica) que el fin (el comercio), por lo que sus desarrollos sobre el medio son igualmente ilustrativas a efectos de considerar la situación del consumo electrónico.

En cuanto a la terminología se entiende que los consumidores son destinatarios finales de los bienes o servicios adquiridos y los consumidores no usarán dichos bienes o servicios con fines lucrativo empresariales de manera directa. El ciberconsumidor debe ser protegido ya que es considerado la parte débil dentro de la relación jurídica de consumo.

Los cuatro países de la CAN, tienen legislación de defensa del consumidor, y en ellos si bien existen particularidades regulativas, coinciden en los derechos de los consumidores fundamentados en los Derechos Humanos.

Bolivia es el único que no reconoce expresamente el derecho a la constitución de asociaciones de consumidores, sin embargo que ello igualmente está garantizado por la Constitución Política del Estado de Bolivia.

La legislación colombiana contempla los derechos de los ciberconsumidores, tales como a: la identificación comercial del empresario, la información digital del producto ofertado, la información sobre los medios de pago, la entrega del producto, al retracto y condiciones del contrato, la constancia de la transacción, la protección de datos del ciberconsumidor, un soporte digital brindado por el proveedor y la reversión del pago.

En la legislación ecuatoriana se identificaron los derechos implícitos a la información digital y a la reversión, y en el caso de Perú está contemplado derecho a la protección contra los métodos comerciales agresivos o engañosos alcanzando dicho derecho a los contratos a distancia con lo que ingresa dentro del consumo electrónico.

De la comparación jurídica se identifican las particularidades y las semejanzas en cuanto a los principios y derechos.

Asimismo se identifica el avance de Europa y el Mercosur a efectos de ver cómo la temática puede tratarse en un escenario comunitario, teniendo ambos bloques realidades totalmente distintas sin embargo ambos contemplan la pertinencia del tratamiento comunitario de la protección de los consumidores. En Europa ya existen Reglamentos europeos en distintas áreas vinculados con el derecho de los consumidores, lo que nos brinda un claro argumento de la pertinencia de tratar nuestra problemática a nivel subregional de la CAN. 
Se debe hacer un planteamiento jurídico a nivel subregional ya que carecemos de un marco jurídico internacional aplicable a las relaciones de consumo de los países de América Latina con el resto del mundo comercial.

Con todo lo referido parece legítimo y pertinente plantear el establecimiento de una Decisión en la Comunidad Andina de Naciones que tenga por objeto la adopción de una norma comunitaria en materia de protección de los derechos de los ciberconsumidores, sustentando nuestra posición en fundamentos jurídicos y económicos que hacen viable dicho proceso armonizador, recordando que el art. 3 del Acuerdo de Cartagena de la CAN establece que: "Para alcanzar los objetivos del presente Acuerdo se emplearán, entre otros, los mecanismos y medidas siguientes: b) La armonización gradual de políticas económicas y sociales y la aproximación de las legislaciones nacionales en las materias pertinentes", lo que nos otorga un mandato normativo claro y concreto a efectos de sustentar de nuestra parte una postura armonizadora de los derechos de los ciberconsumidores.

Finalmente, se plantea la creación de un Defensor del Consumidor Andino como institución encargada de la protección de los ciberconsumidores y también se plantea la utilización de las funciones arbitrales del Tribunal Andino de Justicia como mecanismo de resolución de disputas entre ciberconsumidores y proveedores.

\section{REFERENCIAS}

Cendoya, J. (2001) La Protección de los consumidores, en Derecho de Internet contratación electrónica y firma digital. Navarra: Arazandi, Base de datos jurídicos.

Comisión de las Naciones Unidas para el Derecho Mercantil Internacional (CNUDMI). Legislación Informática de la ONU. (2001). Ley Modelo sobre Comercio Electrónico y una Ley Modelo sobre Firmas Electrónicas.

Constitución Política de la República del Ecuador. Asamblea Nacional Constituyente del Ecuador. Registro Oficial 449 de 20 oct 2008.

Constitución Política del estado Plurinacional de Bolivia (2009, Febrero 7). República de Bolivia.

Corte Suprema de Justicia. Sala de Casación de la República de Colombia, 2010.

Davara, de Marcos, I. (2008) Breve aproximación a la problemática jurídica del comercio y la contratación electrónicos y a la firma electrónica en particular. en Estudios en Homenaje al Dr. Fix Zamudio, Tomo XII. México: UNAM.

Directiva 97/7.Parlamento Europeo. Disponible: https://eur-lex.europa.eu/legal-content/ES/ ALL/?uri=celex\%3A31997L0007
Econsumer, Informe de Evolución y perspectivas ecommerce (2011) (2018)

El Tratado de Maastricht. Tratado de la Unión Europea. (1992). Parlamento Europeo. Disponible: https://www.europarl.europa. eu/about-parliament/es/in-the-past/theparliament-and-the-treaties/maastrichttreaty

Feldstein de Cárdenas, S. y Klein, L. (2011). La noción del consumidor en el Mercosur. Revistas Uc3m. Madrid: Universidad Carlos III.

Harvey Nash, 2020. KPMGCIO Survey 2020: Todo ha cambiado. ¿Seguro? [Página Web]. Disponible: https://home.kpmg/es/es/home/ tendencias/2020/10/harvey-nash-kpmg-ciosurvey-2020.html

Ley Orgánica de Defensa del Consumidor (LDC) (Ley No. 2000-21) (2000). República del Ecuador. Asamblea Nacional Constituyente del Ecuador.

Ley 148012 (2011, octubre12). Estatuto del Consumidor. Congreso de Colombia. República de Colombia 